\title{
La programación televisiva del tardofranquismo: la propaganda en las emisiones de entretenimiento y divulgación*
}

\author{
Television programming during late francoism: \\ propaganda in entertainment and disclosure emissions
}

\section{Tamara Antona}

Universidad Internacional de La Rioja, España.

tamara.antonaQunir.net

\section{Resumen}

El objetivo de esta investigación es determinar en qué medida la programación televisiva tenía elementos que reforzaban la figura del Estado, en el periodo denominado Tardofranquismo, en el entretenimiento y la divulgación. Esta etapa se inicia simbólicamente con la designación de Juan Carlos de Borbón como sucesor de Franco en 1969 y concluye con el fin de la dictadura, por lo que se ha establecido como fecha final el 20 de noviembre de 1975. Para ello, el objeto de estudio seleccionado son las parrillas de programación, como fuente primaria. La hipótesis afirma que la televisión era un escaparate para mostrar que la modernidad había llegado a España. El análisis detecta qué tipo de espacios estaban dirigidos a ese fin, en este periodo que comienza con una tímida apertura cultural. Los espacios formativos televisivos fueron muy limitados y los únicos permanentes son los de divulgación de la fe católica. Todos estos elementos no son diferentes a los de otros países europeos. La única salvedad eran los espacios informativos, que mantuvieron un férreo control, y las temáticas moralmente controvertidas o que criticaban al Régimen.

\section{Palabras clave}

Televisión Española (TVE), Programación, Tardofranquismo, Propaganda, Entretenimiento, Espacios Formativos.

\begin{abstract}
The goal of this communication is to determine the extent to which the television programming supported the Spanish government image during Late-Francoism. This period symbolically started with the designation of Juan Carlos de Borbón as the natural successor of Franco in 1969, and ended with the death of the dictator. The object of study are the programming lists (the grills), as the primary source. The hypothesis is that the official television message was to show that modernity had come to Spain. The analysis aims to identify what kind of spaces were intended for that purpose. In this period a timid cultural openness begins. The formative spaces were quite limited and the only ones who remained were the programs focused on the divulgation of the Catholic faith. All these elements are no different from other European countries. The only exceptions were the newscasts, which maintained a tight control until the end, when morally controversial themes or criticisms to the Régimen were concerned.
\end{abstract}

\section{Key words}

Spanish Television (TVE), programming, Late-Francoism, Propaganda, Entertainment, Formative programs

\footnotetext{
* Esta investigación se ha realizado dentro del proyecto de investigación Televisión y Cultura popular durante el franquismo: Programación, programas y consumo televisivo (1956-1975)", ref. HAR2011-27937; y dentro del Grupo Complutense de Investigación consolidado Historia y Estructura de la Comunicación y el Entretenimiento (n 940439), de la Universidad Complutense de Madrid (España).
} 


\section{Introducción}

El 28 de octubre de 1956 comenzaban las emisiones regulares de TVE. La televisión llegó a una España que comenzaba a prosperar después de veinte años de miseria. La Guerra Civil (1936-39), la posguerra, el revanchismo político y el aislamiento internacional hicieron que durante dos décadas los españoles tuvieran como preocupación principal cubrir las necesidades básicas. Sobrevivir. El final de la Autarquía económica y los Planes de Desarrollo puestos en marcha en los sesenta, así como la llegada de divisas procedentes de la emigración, propiciaron que la economía española despegara en los sesenta (Tamames, 2005). En el acto oficial de inauguración de las emisiones oficiales, el director de Programas y Emisiones de TVE, José Ramón Alonso afirmó que la televisión comenzaba precisamente el 26 de octubre, por ser el día de Cristo Rey, y que los dos caminos que habían trazado desde la dirección de TVE eran "servir a Dios" y a "la política española"1. La televisión en esos años era el símbolo de la sociedad de consumo y de los cambios sociales (Montero, 2014). Era un bien que apareció como un elemento de lujo, inalcanzable para la mayoría de la población por su precio ${ }^{2}$, con una programación muy limitada en tiempo y espacio; exclusivamente tres horas de programación diaria, que llegaban a Madrid y alrededores, en sus primeros meses (Antona, 2016). En menos de una década, el parking de televisores se disparó ${ }^{3}$, las emisiones cubrían casi la totalidad de la jornada (salvo las noches) y la señal podía recibirse en la mayor parte del territorio nacional. Es más, se abrió un segundo canal, La 2 (en 1966), y gracias a los acuerdos internacionales, TVE tenía acceso a los contenidos de la Red de Eurovisión y podía conectar vía satélite con el otro lado del océano Atlántico (Baget, 1992). La televisión en los sesenta representa el cambio de una nueva generación de españoles que crecieron formando parte de esa sociedad de consumo. La dictadura autoritaria se preparaba a finales de los sesenta para el continuismo político, puesto que lógicamente se necesitaba un sucesor para Franco (Montero, 1998). Dentro de este contexto, este artículo se va a centrar en la etapa final de la televisión durante este periodo, que se denomina Tardofranquismo y que arranca simbólicamente con el juramento de Juan Carlos de Borbón al principio del del Movimiento Nacional y su designio como como sucesor de Franco el 22 de julio de 1969 ante las Cortes.
En este contexto, el nuevo medio de comunicación era una herramienta muy poderosa en lo que a la opinión pública se refiere. El objetivo de este artículo es analizar si la televisión fue una herramienta al servicio del Régimen en este momento político. Se verifica si la televisión tenía la misión de favorecer el continuismo del Régimen y de perpetuar los valores sobre los que se sustentaba el Estado: el Ejército, la Iglesia, la familia y las tradiciones ${ }^{4}$.

\subsection{Antecedentes}

La televisión en España evoluciona en la primera década, al igual que su contexto. Por un lado, los avances técnicos, como la llegada de los sistemas de grabación que facilitan las emisiones, que ya no tienen que ser en riguroso directo (Palacio, 2001) como en sus orígenes. También la propia experiencia de los empleados, así como la llegada de nuevos realizadores, como Narciso Ibáñez Serrador o Valerio Lazarov (Baget, 1992) hacen que el medio poco a poco logre ponerse a la altura de otras televisiones europeas. No así la política. En los sesenta, el fin de la autarquía económica y la emigración internacional (con la consiguiente llegada de divisas) consiguen que la sociedad de consumo despegue poco a poco, pero no las libertades (Montalbán, 1973). La evolución de la televisión es un símbolo de este cambio: la sociedad comienza a imbuirse en el capitalismo, pero continúa cautiva de una dictadura militar personalista, que vive sus etapas finales.

El objeto de estudio seleccionado son las parrillas de programación, como fuente primaria entre los años 1969 y 1975. La programación es el diálogo que la cadena mantiene con su audiencia (Gómez, 2003), por lo que es necesario analizar los elementos que componen ese diálogo en su conjunto, para determinar en qué medida los espacios que tratan de orientar la opinión del público son relevantes por su presencia en antena. Esta investigación tratará sobre tres variables claves que se enmarcan en la composición de la oferta televisiva: el peso de la oferta televisiva que tenía fines propagandísticos, el lugar del día en el que se situaban y qué tipo de programas eran, para esto último se centrará en la temática de las emisiones localizada en las parrillas. 
La hipótesis de partida de este estudio es que el mensaje oficial de la televisión durante el Tardofranquismo era mostrar y demostrar que la modernidad había llegado a España. Es decir, un mensaje que pretendía extender la idea de continuismo político y su normalización.

El encargado de llevar esos nuevos aires a la televisión fue Adolfo Suárez $z^{5}$ tras su llegada a la Dirección General de RTVE entre 1969 y 1973 (Baget, 1992). La televisión de los setenta tiene un modelo de programación muy establecido, fruto de la propia evolución del medio que gracias a los avances técnicos y a la profesionalización de los trabajadores fue aproximándose a los gustos de las audiencias (Antona, 2016). Por lo tanto, la segunda hipótesis es que la televisión tardofranquista no era, o no exclusivamente, una herramienta al servicio de la dictadura, sino que es el resultado de implantación del nuevo medio de comunicación en una sociedad $y$, en esencia, es muy similar al proceso de muchas televisiones coetáneas que se desarrollarán en el panorama europeo. Por ello, las iniciativas en las que se exaltaban los valores de la Iglesia, el Estado, la familia y la tradición, eran minoritarios y fruto de la propia idiosincrasia del país.

Aclarado este punto, el trabajo tiene el objetivo de determinar en qué medida la programación de los últimos años reflejó la situación política española: un país que llevaba treinta años bajo una dictadura personalista militar que se encontraba irremediablemente en sus etapas finales, debido a los problemas de salud del Jefe del Estado, pero que trataba de perpetuarse a través del nombramiento del Príncipe Juan Carlos de Borbón como sucesor.

A la hora de abordar un estudio sobre programación se pueden establecer dos niveles de análisis: el primero es el que se refiere a la composición de las parrillas, qué programas la componen, cuándo se emitían y su relevancia referida al tiempo de emisión. El segundo, es el que desciende al contenido de los programas. Este estudio se centra en el primer nivel, aunque se ha completado con la consulta bibliográfica para completar la fotografía del tipo de programas (sobre todo de ficción) que se emitían. Por último, la historia de la programación puede (debe) completarse con un perfil de la audiencia. Este estudio ha trabajado con fuentes primarias sobre la recepción.

\section{Discusión}

El mensaje televisivo, la programación, se dota de contenido en la recepción (Fiske, 1997: 40). Por eso cada programa puede significar diferentes cosas en función no sólo del receptor, sino incluso del momento del día en que lo vea, ya que cada uno de los espectadores interpretará lo que ve a partir de su propia ideología, creencias y experiencias. Por ello, es necesario en el primer nivel de análisis detectar en qué momento del día se emitían los espacios a fin de determinar a qué tipo de espectadores se dirigían principalmente.

No hay datos referidos a las audiencias reales, pero sí existen publicaciones de encuestas de opinión realizadas por el Instituto de Opinión Pública (Palacio, 2001), o la propia publicación oficial, Telediario (Tele Radio, a partir de 1960), que desde el inicio de la televisión consultaban qué opinaban los telespectadores sobre el medio y la programación 6 .

Este estudio es novedoso porque en los estudios históricos tradicionales sobre televisión en España los investigadores se han centrado en aspectos políticos (Vázquez, 1973; Munsó, 2001), culturales o económicos (Bustamante, 2013; Palacio, 2001). Y las fuentes de información utilizadas para estas revisiones históricas se han centrado, en muchos casos, en la memoria y la revisión bibliográfica, no en análisis de fuentes primarias (desde Baget, 1992 a Lorenzo Díaz, 2006, entre otros muchos). El estudio de la programación tiene un enfoque original para los investigadores españoles. Hay trabajos que han utilizado las parrillas como fuente de análisis. Por ejemplo, las aproximaciones parciales de la programación (Gómez-Escalonilla, 2003) o de un periodo limitado de tiempo (Carreras, 2012). También otras en las que se han abordado cuestiones transversales de la programación como los deportes (Bonaut, 2006), los toros (De Haro, 2016), concursos (Moreno, 2014), documentales (Cabeza, 2013) o infantiles (Paz y Martínez, 2013). Este estudio se enmarca dentro de los Television Studies y pretende aportar un modelo epistemológico de reconstrucción histórica reproducible para futuras investigaciones. 


\section{Metodología}

Para este artículo se han utilizado los resultados del análisis de las parrillas de programación publicadas, rescatadas y contrastadas de tres medios impresos: ABC, La Vanguardia y Tele Radio. El resultado es una base de datos en las que se han registrado todas las emisiones de TVE desde el 1 de enero de 1969 al 20 de noviembre de 1975. La fecha de inicio recoge el comienzo del periodo analizado por año completo, aunque la designación oficial de la sucesión no ocurriera hasta junio. El final de la muestra se corresponde al día de la muerte de Franco. Todas las emisiones se han clasificado en tres bloques que coinciden con las funciones clásicas de la televisión (Camacho, 2005): el informativo, el entretenimiento y el divulgativo. Esta investigación se ocupará de las emisiones que pertenecen al bloque divulgativo y a las de entretenimiento. Los informativos y los programas dedicados a la actualidad a finales de los sesenta representaron prácticamente el 25 por ciento del tiempo total emitido (Tabla 1). No obstante, para determinar de qué forma los espacios informativos sirvieron como vehículo de propaganda política es necesario realizar análisis de contenido de los mismos, lo cual merece un estudio propio ${ }^{7}$, y en cualquier caso siempre sería mediante una aproximación parcial, pues solo se conservan (algunas) partes de emisión, no las grabaciones de estos espacios. La censura y el control informativo que sufrió TVE hasta el final de la dictadura está fuera de discusión, por lo que, este artículo solo se ocupará de algunos tipos de contenidos de entretenimiento (cuyo bloque contó con aproximadamente el 63 por ciento del tiempo de emisión) y de los programas de divulgación (con el 11 por ciento). El reparto de los tiempos no fue igual en todo el periodo, como se refleja en la siguiente tabla:
Los bloques de entretenimiento y divulgación se han dividido en tipos de programas ${ }^{8}$. Dentro del bloque divulgativo hay programas documentales, culturales, religiosos, educativos y formativos. Este estudio se centrará en el análisis de la programación de la totalidad de los espacios situados en este bloque entre 1969 y 1975, con especial atención a los formativos y los educativos. Además, se analizarán las temáticas de los espacios culturales y documentales.

Por otra parte, dentro del bloque de entretenimiento, se analizarán las temáticas generales (localizadas a través de bibliografía, o Bases de Datos online) de los programas de producción nacional: tanto los televisivos, como los cinematográficos emitidos por televisión. Inicialmente se ha tratado de localizar algún espacio que contuviera elementos contrarios a la percepción tradicional franquista de la sociedad, basada en la tradición y la religión o culturalmente aperturistas (como adaptaciones de obras o cine de autores que en otros momentos de la dictadura no estaban permitidos) para determinar si su presencia es representativa y ascendente o puntual. No obstante, el resultado de esta búsqueda en el grueso de la programación, fue negativo. Por otra parte, tras la revisión bibliográfica, sí se han identificado líneas comunes de argumentación en la ficción propia (contenidos familiares, costumbristas, centrados en la clase media-altal y un espacio concreto con guión original de TVE cuyo fin inicial era la difusión del Fuero de los Españoles (1945): Crónicas de un pueblo (1971-1974).

\section{Gráfico 1: Porcentaje de la distribución de los bloques 1969-1975}

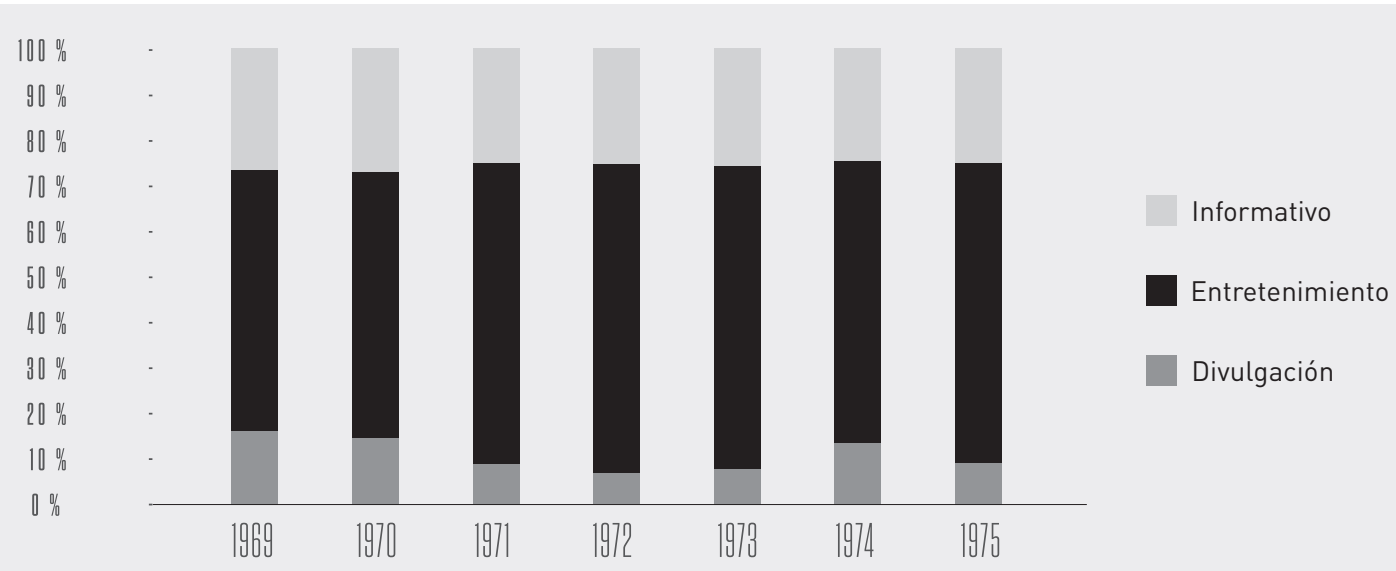

Fuente: Elaboración propia a partir de la información de ABC, La Vanguardia y Tele Radio. 


\section{Tabla 1: Tipos de emisión de cada bloque de programación y variables analizadas}

\begin{tabular}{|c|c|c|}
\hline Ficción extranjera seriada & Series de producción ajena & No se analizan \\
\hline Ficción propia & Producciones propias de TVE: tanto dramáticos como series españolas & Temática \\
\hline Ficción no seriada & Largometrajes, fundamentalmente & Temática y nacionalidad \\
\hline Concursos & Emisiones en las que hay una competición para conseguir un premio & No se analizan \\
\hline Espectáculo & Programas de variedades, humor, realities, danza, folclore y magazines & No se analizan \\
\hline Musical & $\begin{array}{l}\text { Espacios en los que la música y las actuaciones en directo o diferido son } \\
\text { el argumento }\end{array}$ & No se analizan \\
\hline Infantiles & Programas específicamente diseñados para el público infantil o juvenil & No se analizan \\
\hline Deportivos & Retrasmisiones deportivas & No se analizan \\
\hline Taurinos & Retrasmisiones de corridas de toros, novilladas, encierros, etc. & No se analizan \\
\hline Otros & Espacios de entretenimiento de daban continuidad a la programación & No se analizan \\
\hline Documentales: & Tanto los de producción de TVE coimo los importados & Temática \\
\hline Culturales: & Espacios de contenido cultural (literatura, arte, sobre ciencias, etc.) & Temática \\
\hline Educativos: & $\begin{array}{l}\text { Programas de transmisión de conocimientos reglados, como cursos de } \\
\text { idiomas o de alfabetización. }\end{array}$ & Análisis de programación \\
\hline Formativos: & $\begin{array}{l}\text { Espacios de enseñanza no reglada y trasmisión de valores morales, cívi- } \\
\text { cos y religiosos. También las retrasmisiones militares y religiosas. }\end{array}$ & Análisis de programación \\
\hline
\end{tabular}

Se han seleccionado dos tipos de variables temáticas: las que exaltaban la figura de la tradición española, por ejemplo a través de las viejas glorias del Imperio Español, o a través de logros o avances de insignias patrias, y por medio de la exaltación de éxitos militares e históricos; y, por otra parte, en la ficción se han buscado temáticas que la Ley de Prensa de 1966 establecía como censurables. En concreto son tres discursos ideológicos contrarios al Régimen que se han buscado a la hora de determinar estos espacios: cualquier tema que afecte a la moral sexual, que ataque el dogma católico u ofenda a sus representantes o, por último, que socave los principios políticos del régimen o confronte a sus instituciones.

\section{La religión y el patriotismo como pilares de la propaganda}

Dentro de los espacios de divulgación hay dos variables que representan el contenido político del Franquismo: el primero de ellos es la utilización de la fe católica como canal de adoctrinamiento en los espacios de formación religiosa conducidos por Monseñor Guerra Campos en los años setenta (Peñuelas, 2004). La segunda es la utilización de la televisión como herramienta formativa, que tenía la misión de orientar y educar al espectador en su papel como ciudadano. El eje común de todos ellos era el servicio público, entendido desde la mentalidad de que la televisión ejerce de soporte vital para los valores ${ }^{9}$ sobre los que se sustenta el Estado. Los espacios formativos a lo largo del periodo se encuentran con cuatro sub-categorías: los espacios para mujeres len los que se enseñaba desde cocina, moda o lo que se esperaba de ellas en su labor de hija, madre y esposa ${ }^{10}$ ), para hombres jóvenes la los que se les ofrecían enseñanzas útiles 
para el futuro, orientación e incluso formas de ocio), hombres maduros (relacionadas con temas castrenses y de funcionamiento interno del Estado ${ }^{11}$ ], servicios al ciudadano ${ }^{12}$ y la formación religiosa, que son prácticamente los únicos que permanecen en la parrilla de programación a partir de 1970, es decir, que uno de los primeros cambios que se produjeron en TVE, posterior a la llegada de Suárez, fue la eliminación de los programas de corte más propagandístico, aunque la religión siguió estando presente en televisión. A finales de 1970 se incluyó el espacio Las instituciones (1974-1975), de periodicidad semanal y que tenía la misión de explicar el funcionamiento político del Estado a los españoles. Un ejemplo de legitimación y normalización de la situación política, que pretendía perpetuarse luego de la muerte del dictador, el cual se encontraba ya muy enfermo.

Durante la época analizada la Iglesia católica comenzó un proceso de diferenciación con el Régimen de Franco propiciado por Juan XXIII y continuado por Pablo VI, que tenía como brazo ejecutor a Vicente Enrique y Tarancón, que desde el año 1971 presidía la Conferencia Episcopal ${ }^{13}$. No obstante, desde la Iglesia española, existía un profundo apoyo a la Dictadura personificado, entre otros, por Guerra Campos, que fue además el presidente de la Comisión Asesora de Programas Religiosos de RTVE hasta 1973. Él mismo estuvo detrás de espacios como El octavo día (1972-1973) que criticaba todo viso de libertad que el nuevo ministro Pío Cabanillas propugnaba. No obstante, no todos los espacios religiosos tenían una tendencia continuista tan pronunciada: en aquellos años se estrena el programa Ronda familiar (1972-1974), con guión del jesuita Antonio Sobrino. El espacio estuvo presentado por Ángel Losada y Maribel Trenas, se emitió en la sobremesa de los viernes y, como su antecesor, Ojos nuevos, era un tele-magazine de temática religiosa. En el año 1974 lo sustituye Pulso de fe (1974-1975) de Salvador Muñoz Iglesias. La temática religiosa se completa con El día del Señor y la misa dominical que se emite a continuación. El resto del culto televisado en la etapa final del franquismo correspondió a festividades como la Semana Santa o espacios diarios de oración como Un momento por favor (1974).

La llegada de Suárez supone también la desaparición de los espacios educativos, los que impartían lecciones regladas de la parrilla. A lo largo de los sesenta, la tarde tuvo un espacio reservado de dos horas para el Bloque Cultural. En él se incluían desde lecciones de idiomas (tanto de inglés y francés, presentes desde 1958 a 1967 con diferentes títulos), espacios de cultura general (de diversas temáticas), clases magistrales de catedráticos universitarios (Universidad TV, 1959-1964) o programas con un claro contenido educativo (Academia TV, 1962-1964; Escuela TV, 1961-1963; o Bachillerato TVE, 1963-1965, entre otros) y hasta de alfabetización (Imágenes para saber, 1966-1967). El último fue Televisión Escolar (1968-1970), una iniciativa de carácter europeo para la que TVE copió el modelo de otras cadenas como la RAl que se emitía en horario de mañana con el fin de complementar la escuela tradicional. En él se emitían de lunes a sábados lecciones de matemáticas, lengua, naturaleza o ciencias para que los telespectadores y los estudiantes desde sus respectivas escuelas pudieran seguir los contenidos.

Por su parte, los espacios culturales en los años setenta, muy numerosos en la etapa anterior -con cerca del 5 por ciento del porcentaje total de minutos emitidos entre 1958 y 1968 (Antona, 2016)prácticamente desaparecen $(2$ por ciento de media anual, aunque entre 1971 y 1975 apenas suponen el 1 por ciento del total del tiempo de emisión). La causa estaba directamente relacionada con la adaptación de los contenidos televisivos al propio medio: los espacios de busto parlante comenzaban a estar obsoletos y la cultura se canalizó por medio de otros formatos, como los documentales, los cuales tuvieron su máximo esplendor precisamente en esta época. En cuanto a la temática de estos, cabe destacar que los temas históricos (España, Siglo XX, 1970-1973, o La huella del hombre, 1969-1970) y etnográficos (Raíces, 1974-1975) fueron muy recurrentes en las series documentales (Hernández, 2008) producidas por TVE. Aunque su localización en parrilla hace pensar que eran bien recibidas por el público, nunca gozaron de la misma popularidad que el género de la naturaleza, que fue la estrella de los documentales en los setenta. La persona que se encargó de acercar el medio ambiente a los salones de los espectadores de TVE fue Félix Rodríguez de la Fuente ${ }^{14}$.

El patriotismo y la exaltación de "lo español" como elemento de admiración en la etapa final de la televisión franquista se pueden encontrar en Lo que va de siglo (1968-1969) ${ }^{15}$, espacio en el que se exaltaba la cultura española del siglo XX a través de la reconstrucción de testimonios e imágenes fil- 
madas para la ocasión o extraídas desde archivos. En esta temporada se estrenó también Pueblos de España, también llamado Pueblos que dejan huella (1968-1969) programa que recuperaba la temática etnográfica que los hermanos Caro Baroja habían llevado a TVE a mediados de los sesenta ${ }^{16}$, y que dedicaba un capítulo a una población española, aunque no tuvo mucho éxito dado que contó con muy pocas emisiones. El documental etnográfico retorna de nuevo a finales de los setenta con el espacio Raíces (1975) una serie documental dirigida por Manuel Garrido Palacios, en el que se daban a conocer las costumbres y tradiciones de los pueblos de España. Los documentales históricos que abordaban la historia nacional fueron, los ya mencionados, España siglo XX y La huella del hombre, además de La noche de los tiempos (1971-1972) y Tiempos de España (1975). Reconstruyendo, en el primer caso, la historia del país desde la Guerra de Cuba hasta la fecha de emisión, en el segundo la cultura y en el tercer programa los orígenes antropológicos. España siglo XX y La noche de los tiempos fueron muy bien consideradas por el público, prueba de ello son sus localizaciones en parrilla, además en 1972 compartieron el premio Ondas al mejor programa cultural. En Tiempos de España, con guión y dirección de Ricardo Blasco, se repasa la historia reciente de España con capítulos que dividen el periodo estudiado de forma cronológica ${ }^{17}$. La utilización de la exacerbación patriótica no es exclusiva de la divulgación, dentro del entretenimiento también se encuentran estos patrones.

\section{El entretenimiento como espejismo de los nuevos aires de libertad}

A la hora de hablar de propaganda a través del entretenimiento, lo primero que cabe destacar es la exaltación de los éxitos deportivos y la asunción de los mismos como éxitos propios del Estado, hechos mediáticos ampliamente tratados por la bibliografía Bonaut (2006). El ejemplo más utilizado tradicionalmente es el de la exaltación de los triunfos que cosechó el equipo de fútbol Real Madrid y el triunfalismo con el que el Estado los abanderaba sobre todo de cara a los españoles y también hacia el exterior. La retransmisión futbolística fue utilizada como un símbolo de cara a la audiencia: el mejor vehículo para demostrar las capacidades de la nueva tecnología fueron los partidos en los que el Real Madrid se enfrentaba contra su máximo rival, el Barcelona ${ }^{18}$, para demostrar que la conexión entre Madrid y la Ciudad Condal estaban establecidas o los partidos del exitoso Real Madrid de Di Stefano ${ }^{19}$. No obstante, el fútbol no fue el único deporte que sirvió de exaltación patriótica: durante todo el periodo se retransmitieron los éxitos deportivos de España (Bonaut, 2006:285) ${ }^{20}$, lo cual, servía por un lado para presentar de cara al exterior las virtudes de España y de cara al público nacional era una oportunidad para festejar de manera conjunta, reforzando así la idea de una nación, los éxitos cosechados por el deporte español.

La ficción también servía de forma transversal como vehículo para emitir el mensaje de que algo estaba cambiando, aunque los intentos de esto fueron bastante anecdóticos en el Primer Canal: los largometrajes emitidos eran los más populares, destinados a un público mayor y más heterogéneo. En el segundo canal, La 2, se programaron, entre otras, producciones que habían sufrido problemas comerciales o de censura en el momento de su estreno, incluso, en muchas ocasiones, en versión original (Martín, 2015).

La exhibición de largometrajes en TVE se encontró desde el inicio con el enfrentamiento de las salas de cine, por lo que el cine que se emitió en TVE durante la década de los sesenta estuvo muy influenciado por esta disputa (Gil, 2014): eran películas muy antiguas y muy pocas españolas ${ }^{21}$. En los setenta, la televisión ya tenía definidos los contenidos que mejor encajaban en la programación y la ficción seriada fue el pilar fundamental sobre el que se cimentó el entretenimiento. Las películas no dejaron de ser un contenido que, aun siendo del agrado del público, llegaba con bastante retraso respecto a los estrenos de cine por lo que, poco a poco, ambos medios comenzaron a colaborar y retroalimentarse. Incluso, se comenzó a reivindicar una mayor presencia del cine español en TVE. En el espacio Hoy presenta, título con el que se anunciaba la película de la noche de los jueves, se trató de "rehispanizar" la televisión a través de la incorporación de películas de producción nacional. Las producciones norteamericanas fueron las que más representación tuvieron en parrilla ${ }^{22}$. 
A partir de 1971, el cine español contó con más presencia gracias a la organización de ciclos que se programaron tanto en la franja de tarde del sábado, como en la noche. Esa temporada fue en la que más películas españolas se emitieron en TVE con un total de veinte títulos, organizadas en torno a dos ciclos concretos: un ciclo de Marisol $^{23}$ en la programación de tarde de los sábados del mismo año y otro de cine español de humor con títulos como Deliciosamente tontos (Juan de Orduña, España, 1943), Los dinamiteros (José Isbert, España, 1962) o Atraco a las 3 (José Ma Forqué, 1963). A pesar de la enorme acogida del cine español, la disputa presente con las exhibidoras no permitió incluir más producciones nacionales en TVE (Zahedi, 2014). A finales de 1971 y principios de 1972 se emitió otro ciclo de cine español en el que se programaron once títulos entre los que estaban Doña Francisquita (Ladislao Vajda, España, 1952), La nao capitana (Florián Rey, España, 1946), Locura de amor (Juan de Orduña, España, 1948), Jeromín (Luis Lucía, España, 1952) o Garbancito de la Mancha (José Ma Blay, España, 1945) el primer largometraje de dibujos animados español y el primero en color de toda Europa. Todos esto títulos, con temáticas bastante patrióticas que ensalzaban lo mejor del producto y la historia nacional. En 1974, durante la llamada Primavera del Aperturismo, la Jefatura de Programas fue asumida por Narciso Ibáñez Serrador, un realizador que ya había traído la modernidad a la realización de la ficción con realizaciones como Historias para no dormir (1966-1968). Una de las incorporaciones más sorprendentes de la parrilla fue la inclusión de un nuevo ciclo de cine español en el que había una película de Juan Antonio Bardem, marcado por un pasado comunista (La muerte de un ciclista, 1955) - Carlos Saura (El Llanto por un bandido, 1964, filme que contaba con la colaboración del proscrito Luis Buñuel). La tercera película en emitirse, también un tanto comprometida, teniendo en cuenta el contexto, fue La tía Tula (Miguel Picazo, 1964), una libre adaptación de la obra homónima de Miguel de Unamuno en la que narra la lucha interna de la protagonista con sus deseos en aras de preservar la férrea moral imperante. Tras la dimisión en junio del mismo año de Ibáñez Serrador, el ciclo español continuó, pero con títulos menos polémicos.

En el ámbito de la ficción, como contexto general cabe referirse a las series de producción extranjeras. Desde 1957 TVE emitió producciones que mostraban cuán diferente era el mundo exterior, aunque no se ha encontrado ningún cambio que pueda explicarse por razones propagandísticas en los títulos seleccionados para su emisión en TVE. Eso sí, la mayoría de ellas de corte familiar y no trataban temas sujetos a controversia moral. Las razones responden más bien a la oferta de las distribuidoras y a la demanda de las audiencias. Las temáticas del Lejano Oeste como Bonanza o El Virginiano y policiacas como El Agente de C.I.P.O.L. o Hawai 5.0, así como las comedias estuvieron entre las mejor valoradas por los paneles de aceptación de Tele Radio. Además, los espacios infantiles, los cuales cada vez contaban con más presencia en la pantalla, en los setenta ya responderán a un modelo puro de entretenimiento: ya no habrá iniciativas como Jardilín ${ }^{24}$ o Lección de ocio ${ }^{25}$, en las cuales, en cierto modo, se trataba a los niños como adultos en pequeño, a los cuales se debía inculcar en la medida de lo posible ciertos valores, como el empleo útil del tiempo (Paz y Martínez, 2013:305). En los setenta triunfan espacios como La casa del reloj o El Gran Circo de TVE, éste último se situaba en los primeros puestos de los paneles de aceptación ${ }^{26}$ y sus emisiones se prolongaron, con diferentes nombres pero con los mismos protagonistas, hasta los años noventa.

En cuanto a la ficción de producción nacional, en los setenta las dramáticos y las series televisivas estaban ya claramente diferenciadas. Las primeras, que corresponden a las adaptaciones literarias, en algunos espacios como Cuentos y Leyendas (Fernández, 2010:315-316) o Los libros (Fernández, 2010:184), a través de los grandes clásicos se mostraron algunas escenas de pobreza, corrupción o desigualdad, en definitiva, crítica social gracias a la adaptación de obras literarias. Esta permisividad fue un modo de mostrar a la audiencia un espejismo de libertad (Baget, 1992:301).

En la ficción de producción propia con guión original de TVE los contenidos fueron sobre todo de temática familiar, con argumentos que versaban sobre temas cotidianos, muy locales y muy cercanos, del día a día de la sociedad española, en muchas ocasiones urbana, y ambientadas en el presente. En resumen, estos espacios ofrecían una visión amable de la realidad, casi siempre con final feliz, con el fin de entretener al espectador con muchas escenas basadas en los diálogos, localizadas en interiores, que no hacían avanzar la acción. A principios de los setenta llegó Crónicas de un pueblo, un espacio cuyo origen fue abiertamente la utilización 
de la ficción como vehículo de transmisión de los valores del Gobierno ${ }^{27}$. El guión partía del Fuero de los Españoles ${ }^{28}$. No obstante, la ausencia de contextos rurales en la ficción nacional realizada hasta el momento, y la profesionalización de las técnicas de producción televisivas, así como las nuevas técnicas (Canós, 2015), son dos de las poderosas razones que consiguieron la gran aceptación del público; es decir, no es posible determinar hasta qué punto la serie adoctrinó al público o simplemente lo entretuvo. De hecho, hay que añadir que la sociedad de los setenta tenía fuertes lazos con el campo: a pesar del crecimiento de las ciudades, la fuerte emigración de los sesenta hizo que mucha gente que había nacido y crecido en un pueblo, viviera en una urbe, y existir el hecho de ver reflejados sus años de juventud en la televisión. Cabe añadir el efecto realidad que derivaba de los personajes, los diálogos y las tramas, y la amplia presencia de localizaciones exteriores, mucho más numerosas que en las series de producción nacional emitidas hasta entonces (Rueda-Laffond, 2006:15-16).

\section{Conclusiones}

La televisión en España, a pesar del contexto político en el que se desenvolvió, tuvo un desarrollo y una consolidación que dependen en primera instancia de la propia capacidad del medio. Es decir, que los motivos políticos fueron una circunstancia más en la implantación de la televisión, y el hecho de que algunos de los contenidos mostraran de forma clara los valores promulgados, como en el caso de los espacios de Guerra Campos, o que se emitieran películas o temáticas que no pasaban la censura; lo que permaneció imperturbable hasta el final del franquismo. De los principales resultados de la investigación se concluye que no hay elementos que permitan determinar un cambio profundo en la programación de televisión. De hecho, la primera prueba de ello es que no se había localizado ningún programa en el que se contravinieran los valores del nacional-catolicismo. La práctica habitual de la programación televisiva era evitar y sortear los temas que pudieran "disgustar" al Gobierno. Estos contenidos quedaron expresamente recogidos, en la Ley de Prensa de 1966, en la que se eliminaba (entre otras actuaciones) la censura previa. A partir de la llegada de Adolfo Suarez a la dirección de RTVE en 1969, se aprecia la estabilización de una televisión monopolista de corte generalista cuya intención principal es el entretenimiento, a pesar de no olvidar la labor informativa al servicio de las audiencias lotra cuestión es ya qué tipo de información se ofrecía y cual no, o en qué grado estaba manipulada y puesta al servicio del Estado). Pero sí es posible determinar que el espacio en parrilla lo tenía: una cuarta parte de los minutos estaban destinados a información.

La misión formativa de la televisión se adapta al medio y por lo tanto al propio entretenimiento que él emana: los espacios ya no tienen un formato radiofónico, sino que utilizan los recursos audiovisuales para llegar de forma eficaz a las audiencias. La estructura de la programación es moderna (Antona, 2016) y con contenidos fácilmente predecibles para los espectadores.

Lo que sí es cierto es que la aparición de espacios como Las instituciones o Las Cortes fueron tímidos esfuerzos gubernamentales de normalizar la situación política anómala de la España de los años setenta. Lo mismo ocurrió con iniciativas como Crónicas de un pueblo. A pesar de que en su concepción fuera un producto que trataba de promulgar el Fuero de los Españoles, el propio medio consiguió diluir el espacio en un flujo de programación que en última instancia buscaba satisfacer. La televisión de los setenta se centró en entretener. Si ese entretenimiento trataba de desviar la atención de los espectadores de los problemas políticos y sociales (Vázquez, 1973), es otra discusión y no forma parte del objeto de estudio de esta investigación.

Lo que sí se puede concluir es que el objetivo de la programación como flujo -television flow (Williams, 2003)- de TVE no era la exaltación directa del Régimen de Franco, sino que satisfacer a las audiencias, en primera instancia. Durante todo el periodo, la relación del Gobierno con los medios de comunicación fue de control ideológico, en mayor o menor intensidad (Sevillano, 1998), con censura previa hasta la ya mencionada Ley de Prensa en 1966. La televisión pública de un estado autoritario ${ }^{29}$ no permitía mostrar según qué contenidos Icríticas directas o indirectas al régimen, y en este caso además, tampoco temas que atentaran contra la moral cristiana, dado que se trataba de un Estado Católico ${ }^{30}$ ). Lo cual no significa que la televisión fuera un instrumento al servicio del régimen encargado de alienar a los espectadores, dado que la Teoría de la Aguja Hipodérmica estaba superada, incluso en España. En los setenta ya había una generación entera de televidentes que había creci- 
do con la televisión. La hipótesis sostenida, que el mensaje oficial de la televisión durante el Tardofranquismo era mostrar y demostrar que España estaba al mismo nivel de desarrollo que el resto de países europeos, queda por tanto muy matizada. Con los datos aportados no es posible concluir que fuera una de sus misiones principales, pero tampoco descartar que el interés político fuera ese. Lo que sí es posible, es afirmar que las iniciativas propagandísticas estaban muy poco presentes en la programación. Las temáticas que favorecían los valores católicos o que difundían la fe católica, estuvieron presentes hasta el final del periodo estudiado, no obstante, los espacios relacionados con la exaltación del régimen fueron muy limitados: los Desfiles Militares y los discursos de Franco en Nochevieja. Aunque sí permanecieron los espacios audiovisuales dedicados a la exaltación del orgullo nacional y de "lo español". Pero ese espíritu continuista estaba disuelto en el funcionamiento televisivo.

Por otra parte, las temáticas o los espacios que podrían resultar moralmente inapropiados o incluso críticos con el Régimen se emitieron disimuladamente a través de los clásicos y/o sitiados en otros periodos históricos. A modo de hallazgo de esta investigación se identificó que las iniciativas más aperturistas culturalmente hablando se reducen en el Primer Canal a iniciativas puntuales, como el Ciclo de Cine español emitido en 1974.

Desde el Estado se utilizaba este medio oficial para dar mensajes, o para transmitir ciertas doctrinas sobre las que el Franquismo esperaba que la sociedad se sustentara. Por ejemplo, la moral y la doctrina católica. Pero la tónica general fue más que de acción de omisión. Es decir, los temas que no se podían mostrar y las críticas que no se podían verter estaban muy establecidos y TVE los esquivaba. La fe era un elemento más, propio de TVE pero no exclusivo: tanto Irlanda como Italia contaban también con minutos reservados para la religión o para contenidos creados por religiosos y en ambos casos el gobierno era democrático (Menduni, 2004; Savage, 2010).

Por otra parte, el aumento del entretenimiento a principios de los setenta en TVE, sucedió de forma similar en otras televisiones europeas de la época, y tenía como fin principal atraer a la audiencia (Antona, 2016). Es decir, fue una tendencia general de lo que se ha denominado la "ideología del desarrollo" (García-Delgado y Jiménez, 1998): basada en el mito de la europeización, entendido en clave de asimilación de nivel de vida y de consumo entre España y los países de su entorno (Rueda-Laffond, 2005). En este sentido la televisión era un elemento en el que esa estandarización con los patrones europeos era posible.

La relativa libertad en la elección de algunos autores en los espacios de ficción (García, 1980), sobre todo en las producciones que adaptaban guiones clásicos, sirvió para sortear, hasta cierto punto, la norma que la dictadura marcaba. Pero siempre escudada en otras épocas, otras realidades. En términos generales, los profesionales de TVE sabían lo que debían mostrar y lo que no, por lo que se limitaban a las temáticas sin controversia: familiares y cotidianas sin implicaciones políticas.

\section{Notas}

1. Declaraciones recogidas por $A B C$ (30 de octubre de 1956, pp.41).

2. En 1965 solo una tercera parte de la sociedad española poseía un televisor, según las encuestas realizadas por el Instituto de Opinión pública entre 1960 y 1964 (Revista de Opinión Pública. N¹, mayo-agosto, 1965, pp. 227) las razones de la mayoría de los encuestados sobre la carencia del electrodoméstico eran cuestiones económicas.

3. De 25.000 televisores en 1958 a 3.897 .000 en 1969. En Palacio, M. (2001). Historia de la televisióm de España. Barcelona: Gedisa.

4. El Franquismo se caracterizó políticamente por su falta de ideología, aunque los historiadores coinciden en que los pilares ideológicos sobre los que se construyó el régimen fueron estos. En Montero, J. (1998). Constituciones y códigos políticos españoles, 1808 - 1978. Barcelona: Ariel.

5. Tras la muerte de Franco, Adolfo Suárez sustituyó a Arias Navarro como presidente del Gobierno en 1976 y fue una de las personalidades clave de la Transición: en la segunda mitad de los setenta España volvió a convertirse en un país democrático gracias a los cambios políticos que poco a poco se fueron desarrollando en el país. En 1977 Suárez fue elegido presidente del Gobierno en las primeras elecciones celebradas en España desde 1936, año en el que estalló la Guerra Civil. Fue reelegido en 1979 y permaneció en el cargo hasta enero de 1981, cuando presentó su dimisión y fue sustituido por Calvo Sotelo.

6. A partir del número 21 de la revista, se anuncia que TVE comenzará a realizar encuestas telefónicas sobre los espacios de televisión entre los suscriptores. A partir del número 23 se publica de forma regular durante algunos meses un formulario con preguntas sobre la calidad de los programas y datos básicos de las audiencias. Aunque los sistemas de recogida de información de la audiencia son rudimentarios e intermitentes, su mera existencia demuestra la preocupación de la cadena por sus usuarios. Estas iniciativas se prolongaron durante todo el periodo, aunque hasta los setenta no se publicarán de forma regular en los diarios nacionales, como $A B C$ o La Vanguardia, además de en la propia revista.

7. Este estudio además se encontraría con la dificultad de que no quedan grabaciones de los noticiaros, como se señala en Julio Montero et al. (coords.): "Los telediarios franquistas. Una investigación sobre las fuentes" en Revista Latina de Comunica- 
ción Social, Volumen 69, pp. 152-175, 2014. Este artículo utiliza los partes de emisión, que recogen los temas tratados y los videos utilizados, aunque no existe un registro de las noticias en sí, por lo que no es posible analizar el sesgo informativo de las mismas.

8. No se utiliza el término género de televisión porque se ha tratado de preservarla esencia de los programas tal y cómo se anunciaban en los medios, además, se han creado algunas tipologías, como es el caso del tipo de programas formativos que no tienen una concepción genérica propia, sino que aúnan muchos programas y contenidos diferentes. Todos estaban concebidos con el fin de instruir a la audiencia en los valores del estado, el catolicismo o la educación que desde, la Sección Femenina de Falange, se impartía para las mujeres: cómo coser un botón o decorar una casa.

9. Estos valores han sido catalogados y desgranados en profundidad en Pulpillo, C. (2013). “Orígenes del franquismo: La construcción de la "nueva España" (1936-1941), tesis doctoral Universidad Rey Juan Carlos.

10. Por ejemplo, Para vosotras (1963-1964), o La hora de la mujer (1958), Decoración (1958), La moda (1958) o La música y la decoración (1958). Son programas femeninos entendiendo esta feminidad como la imagen que desde el Estado, en general, y desde la Sección Femenina en particular, se trataba de inculcar a la mujer y a la sociedad, a este respecto caben destacar La soltera y su oficio (1960) y Hogar, dulce hogar (1959). Otro ejemplo a este respecto es el espacio Seis mujeres en la vida de un hombre (1964) en el que se explicaba el papel de madre, esposa hermana, hija, etc., que toda mujer representa.

11. Como en Por tierra, mar y aire (1964-1971), Las Cortes (1967) o Las instituciones (1974-1975).

\section{La carretera es de todos (1967-1968)}

13. En el siguiente enlace hay un reportaje del diario El País en el que relata cómo una parte de la Iglesia española decidió desligarse de la política franquista: http://elpais.com/diario/2007/09/13/sociedad/1189634413_850215.html

14. En la encuesta de la revista La Actualidad española (1974) recogida en Historia de TVE (1986), op. cit. pp. 95-96, se recoge que los españoles situaron en segundo puesto en un listado de personajes televisivos más relevantes a Félix Rodríguez de la Fuente, solo por detrás de Los Payasos de la Tele. En 1970 y 1971 había ocupado el primer puesto, el cuarto en 1972 y segundo también en 1973.

15. Emitido los jueves a última hora de la programación de tarde.

16. Con el proyecto Conozca usted España (1966-1969), aunque el ministro Fraga Iribarne consiguió imprimir la promoción turística del país a la idea original. Pío Caro Baroja. (2002). "Recuerdos de un documentalista: Historias de la vieja querida" Pamplona, Pamiela, pp. 150 y Santiago Aumesquet Nosea. (2004). "El documental etnográfico en España: Pío Caro Baroja" Pamplona, Gobierno de Navarra, pp. 50-51.

17. Por ejemplo, en julio de 1975 las emisiones Tiempos de España fueron: 6/07/1975: España ante la Europa de la posguerra: desde 1916 a 1921; el 13/07/1975: España ante la Europa de la posguerra: desde 1916 a 1921 (II); 20/07/2015 España a la busca de una solución: desde 1921 a 1923; 27/07/1975 Orto de la dictadura: de 1921 a 1927.

18. El 15 de febrero de 1959, se retransmitió en directo y generó tanta expectación que los reproductores televisivos se agotaron en la Ciudad Condal.

19. El 18 de marzo de 1960 se había recibido la primera transmisión internacional: la segunda parte del partido entre el Eintracht de Frankfurt y el Real Madrid; con el que el equipo madrileño consiguió su quinta Copa de Europa. El primer programa en directo transmitido desde España a la red Eurovisión, había tenido lugar unos días antes, el 2 de marzo, y también había sido un partido de fútbol entre el Real Madrid y el Olympique de Niza. Para la ocasión se tuvo que instalar una antena a última hora para enviar la señal a Francia, como cuenta La Vanguardia el día anterior, los propios técnicos no estaban seguros de si iba a ser posible la conexión: "No es posible asegurar, dada la complejidad del ajuste de los enlaces, si esta conexión se efectuará mañana, pero, es importantísimo el paso dado por la emprendedora TVE" en La Vanguardia (01/03/1960), pp. 19

20. El autor presenta en una tabla el recuento de minutos destinados a cada disciplina entre 1960 y 1975. El fútbol es el claro vencedor, con 72.358 minutos, seguidos por el baloncesto, con 27.817 y el ciclismo, con 25.526 , todos ellos disciplinas con grandes victorias.

21. Entre 1967 y 1969 se han registrado 344 películas en antena en el primer canal, de ellas, solo 20 eran producciones españolas.

22. Aproximadamente el 85 por ciento de los largometrajes fueron producciones norteamericanas.

23. Marisol era el nombre artístico de una actriz y cantante infantil que se convirtió en una estrella en la España de los sesenta con títulos como Un rayo de luz (Luis Lucia, 1961, por el que recibió el premio a mejor actriz infantil en la Mostra de Venecia), - Ha llegado un Ángel (Luis Lucia, 1962), entre otras (Blanco, 2004).

24. Un espacio basado en la serie de televisión norteamericana Romper Room, destinado a los más pequeños. El objetivo era que aprendiesen a "ser buenos" y para ello se utilizaba al Señor Si, que era un abejorro sonriente y el Señor No era un abejorro enfadado

25. En el que se ofrecían diferentes alternativas para dedicar el tiempo libre de forma provechosa, dirigido a jóvenes.

26. Por ejemplo: en La Vanguardia, 24 de noviembre de 1974, p. 82, El Circo de TVE aparece como el segundo programa mejor valorado, igual que en La Vanguardia, 8 de abril de 1975, pp. 57 , en el que también aparece en segundo lugar y es valorado con un 8,4 sobre 10 por los espectadores.

27. Rueda Laffond (2006) afirma que es una muestra paradigmática en el intento por trasladar a la pequeña pantalla ciertas claves dominantes del imaginario franquista, es un producto de entretenimiento pautado por claves ideológicas. Fue una idea original del vicepresidente del Gobierno Luis Carrero Banco. El objetivo esencial de Crónicas de un pueblo habría de ser el de difundir los preceptos recogidos en el Fuero de los Españoles mediante un formato de relatos de ficción de corte ejemplarizante. No fue casual entonces que el inicio de las emisiones de la serie tuviese lugar el 18 de julio de 1971.

28. Una de las ocho Leyes Fundamentales del franquismo, que establecía una serie de derechos, libertades y deberes del pueblo español.

29. Aún existe discusión sobre la catalogación del Régimen franquista (Linz, 1978), lo que es un hecho no sujeto a discusión es que se trató de una dictadura militar, en la que se coartaron muchas de las libertades fundamentales de los españoles: derecho de expresión, de reunión, de asociación o de culto, entre otros. No obstante, el Franquismo se caracterizó principalmente por su falta de ideología, aunque los historiadores coinciden en que los pilares ideológicos sobre los que se sustentó el régimen fueron la Iglesia y el Ejército, con la familia y las tradiciones como estandartes (Montero, 1998). Tras la sublevación militar en 1936, España estuvo inmersa en una Guerra Civil hasta 1939, cuanto las tropas Franquistas tomaron finalmente la capital. Durante la contienda, el autodenominado Bando $\mathrm{Na}$ cional promulgó el Decreto de Unificación (19 de abril de 1937) en el que se aglutinaban todas las ideologías que componían el Bando Nacional, tratando de aunar fuerzas contra la República. El Régimen que se instauró en España en 1939 ly que permaneció hasta la muerte de Francol fraguó su estructura política a lo largo de los años con las Leyes Fundamentales, aprobadas entre 1938 y 1967. La Ley General de Principios del Movimiento, 
en la que se recogían, como su nombre indica, los principios sobre los que se sustentaba el Régimen (la unidad de España, la Defensa de la Fe Católica, etc) se aprobó en 1958.

30. El 1 de octubre de 1936 (pocos meses después del inicio de la Guerra Civil), Franco es nombrado Jefe del Gobierno del Estado de los territorios controlados por el bando nacional. En su discurso ya recoge la Cruzada en Defensa del Catolicismo. Y en 1945, el Artículo 6 del Fuero de los Españoles recogió el Catolicismo como la religión del Estado Español.

\section{Referencias bibliográficas}

Antona, T. (2016). “La televisión de una audiencia cautiva: historia de la programación durante el franquismo". Tesis doctoral, Universidad Complutense de Madrid. Aumesquet, S. (2004). El documental etnográfico en España: Pío Caro Baroja. Pamplona: Gobierno de Navarra.

Baget, J. (1992). Historia de la Televisión Española. Barcelona. Bellaterra (Publicacions de la Universitat Autònoma de Barcelona).

Bonaut, J. (2006). Televisión y deporte: la influencia de la programación deportiva en el desarrollo histórico de TVE durante el monopolio de la televisión pública (1956-1988). Tesis doctoral, Universidad de Navarra.

Bustamante, E. (2013). Historia de la radio y la televisión en España. Una asignatura pendiente de la democracia. Barcelona: Gedisa.

Cabeza, J. (2017). “Planeta azul (Félix Rodríguez de la Fuente, 1968-74): un laboratorio del documental moderno de naturaleza", Estudio del mensaje periodístico, volumen 20, número especial, pp. 193-208.

Camacho, R. (2005): “Televisión de calidad: distinción y audiencia”, en Comunicar, número 25 , pp. 29-32.

Canós, E. (2015). Los originales de ficción en soporte electrónico de TVE entre 1964 y 1975: conformación y evolución histórica. Tesis doctoral, Universidad CEU Cardenal Herrera (Valencia).

Caro, P. (2002). Recuerdos de un documentalista: Historias de la vieja querida Pamplona: Pamiela.

Carreras, N. (2012). TVE en sus inicios: estudio sobre la programación. Madrid: Fragua.

Fernández, L. (2010). “Cuentos y leyendas (1974-1976)”. En Ansón, A. (ed.), Televisión y literatura en la España de la transición (1973-1982,) pp. 311-316.

Fernández, L. (2014). Escritores y Televisión Durante el Franquismo (1956-1975). CIUDAD.Universidad de Salamanca.

Fiske, J. (2011). Television culture. London: Routledge.

García-Delgado, J. L. \& Jiménez, J. C. (1998). La economía. La época de Franco. Historia de España, XLI. Madrid: Espasa Calpe.

García, J. (1980). Radiotelevisión y política cultural en el Franquismo, CSIC. Instituto Balmes de Sociología, Madrid. 
Gil, F. (2014). “Televisión versus cine. La influencia de los largometrajes emitidos por TVE". Estudios sobre el Mensaje Periodístico, 20, pp. 177-191.

Gómez, G. (2003). Programar televisión: análisis de los primeros cuarenta años de programación televisiva en España. Madrid: Dykinson,

De Haro, M. V. (2016). “Los toros como entretenimiento de masas en la televisión franquista". Communication \& Society 29(3), 69-84.

Díaz, L. (2006): 50 años de TVE, Madrid, Alianza Editorial.

Hernandez, S. (2008). La historia contada en televisión: El documental televisivo de divulgación histórica en España. Barcelona: Gedisa.

Historia de TVE (1986), editada por el diario Ya

Linz, J. (1978): “Una interpretación de los regímenes autoritarios”, en Revista de Sociología, número 8, pp. 11-26

Martín, J. (2015). La programación de la Segunda Cadena de TVE durante el franquismo (1966-1975). Tesis doctoral, Universidad Complutense de Madrid.

Menduni, E. (2004). Televisione e societá italiana. (1975-2000). Milano: Studi Bomtani.

Montero, J. (1998). Constituciones y códigos políticos españoles, 1808-1978. Barcelona: Ariel.

Montero, J., Rubio, Á., Antona, T., Martín, J. \& Fernández, L. (2014). “Los telediarios franquistas. Una investigación sobre las fuentes". Revista Latina de Comunicación Social, 69, 152-175.

Montero, M. (2014). “Los efectos perversos de la publicidad en televisión”. Estudios sobre el Mensaje Periodístico, 20 (número especial),139-156.

Moreno, J. (2014). “Los concursos en España: percepción histórica y evolución del género (1956-1975)". Estudios sobre el Mensaje Periodístico, 20 (número especial), 27-42.

Munsó, J. (2001). La otra cara de la televisión: (45 años de historia y política audiovisual). Barcelona: Flor del Viento Ediciones.

Palacio, M. (2001). Historia de la televisión en España. Barcelona: Gedisa.

Paz, M. A. \& Martínez, L. (2013). “Nuevos programas para nuevas realidades: la programación infantil y juvenil en TVE (1969-1975)". Journal of Spanish Cultural Studies, 14 (3), 291-306.

Peñuelas, M. Á. (2004). “El pensamiento ideológico y político de monseñor Guerra Campos en el horizonte de la Transición inmovilismo y tradicionalismo en el seno de la iglesia". Actas de las VI Jornadas de Castilla-La Mancha sobre Investigación en Archivos, Guadalajara, 4-7 de noviembre.

Pulpillo, C. (2013). Orígenes del franquismo: La construcción de la "nueva España" (1936-1941). Tesis doctoral, Universidad Rey Juan Carlos.

Rueda-Laffond, J. (2006). “Ficción televisiva en el ocaso del régimen franquista: Crónicas de un pueblo". Área Abierta, 14, 15-16.

Savage, R. (2010). A loss of innocence? Television and Irish society, 1960-72. Manchester: Manchester University Press. 
Sevillano, F. (1998). Propaganda y medios de comunicación en el franquismo. Murcia: Publicaciones Universidad de Alicante.

Tamames, R. (2005). La autarquía española y las rémoras para el crecimiento económico posterior. Información Comercial Española (Ministerio de Industria, Turismo y Comercio] [Consultado el 07/03/2016 en: http://www.revistasice.com/ CachePDF/ICE_826_1324_34F2AFD5BC45A2E5A5710C0A1C0C6F55.pdf.

Vázquez, M. (1973). El libro gris de la televisión. Madrid : Edic.

Williams, R. (2003). Televisión: technology and cultural form. New York: Routledge.

Zahedi, F. (2014). "La programación de cine de TVE en la "Primavera del Aperturismo", Estudios sobre el Mensaje Periodístico, 20 (número especial), 243-265.

\section{Hemeroteca}

ABC: Todas la parillas de programación (1958-1975)

La Vanguardia: Todas la parillas de programación (1958-1975)

Tele Radio: Todas la parillas de programación (1958-1975)

Bedoya, Juan G. (2007): El cardenal que hizo llorar a Franco, El País, publicado el 13 de septiembre de 2007, disponible en: [Consultado el 12/09/2016: http://elpais. com/diario/2007/09/13/sociedad/1189634413_850215.html]

ABC: El Ministerio de Información Inauguró oficialmente la televisión en Madrid.

ABC, publicado el 30 de octubre de 1956, p.41

\section{Sobre la autora}

\section{Tamara Antona}

Doctora en Comunicación Audiovisual, Publicidad y Relaciones Públicas por la Universidad Complutense de Madrid. También es Licenciada en Comunicación Audiovisual por la (2008, Universidad Carlos III de Madrid) y Licenciada en en Periodismo de la (2008, Universidad Carlos III de Madrid.) Tiene un Máster en Comunicación Social por la Universidad Complutense de Madrid, con especialidad en Teoría e Investigación.

\section{Cómo citar:}

Antona, T. (2016). "La programación televisiva del tardofranquismo: la propaganda en las emisiones de entretenimiento y divulgación”. Comunicación y Medios, 25 (34), 8 - 21. 